\title{
Neuropeptides as Pleiotropic Modulators of the Immune Response
}

\author{
Luciana Souza-Moreira Jenny Campos-Salinas Marta Caro Elena Gonzalez-Rey \\ Instituto de Parasitologia y Biomedicina 'Lopez-Neyra', Consejo Superior de Investigaciones Cientificas, \\ Granada, Spain
}

\section{Key Words}

Autoimmunity - Inflammation - Neuropeptide $\cdot$ Parasites •

Tolerance $\cdot$ Trypanocidal agent

\begin{abstract}
Although necessary to eliminate pathogens, inflammation can lead to serious deleterious effects in the host if left unchecked. During the inflammatory response, further damage may arise from potential autoimmune responses occurring when the immune cells and molecules that respond to pathogen-derived antigens also react to self-antigens. In this sense, the identification of endogenous factors that control exacerbated immune responses is a key goal for the development of new therapeutic approaches for inflammatory and autoimmune diseases. Some neuropeptides that are produced during the ongoing inflammatory response have emerged as endogenous anti-inflammatory agents that could collaborate in tuning the balanced steady state of the immune system. These neuropeptides participate in maintaining immune tolerance through two distinct mechanisms: by regulating the balance between pro-inflammatory and anti-inflammatory factors, and by inducing the emergence of regulatory $T$ cells with suppressive activity against autoreactive T cell effectors. Indeed, a functioning neuropeptide system contributes to general health, and alterations in the levels of these neuropeptides and/or their recep-
\end{abstract}

tors lead to changes in susceptibility to inflammatory and autoimmune diseases. Recently, we found that some neuropeptides also have antimicrobial and antiparasitic actions, suggesting that they could act as primary mediators of innate defense, even in the most primitive organisms. In this review, we use the vasoactive intestinal peptide as example of an immunomodulatory neuropeptide to summarize the most relevant data found for other neuropeptides with similar characteristics, including adrenomedullin, urocortin, cortistatin and ghrelin.

Copyright $\odot 2011$ S. Karger AG, Basel

\section{Immune Homeostasis: The Daunting Job of the Immune System}

The immune system is perfectly designed to recognize and respond to a wide variety of pathogens and injuries. Once the immune response is triggered, cooperation between innate and adaptive immunity results in the activation of different cell types and immune molecules, which work together to eliminate the damage [1] (fig. 1).

Whereas the inflammatory response plays an essential role in health, disease and survival in all multicellular organisms, its intensity and duration have to be strictly controlled to re-establish immune homeostasis and avoid extensive tissue damage. An insufficient response could

\section{KARGER}

Fax +4161306 1234

E-Mail karger@karger.ch

www.karger.com
(C) 2011 S. Karger AG, Basel

0028-3835/11/0942-0089\$38.00/0

Accessible online at:

www.karger.com/nen
Elena Gonzalez-Rey

Instituto de Parasitologia y Biomedicina 'López-Neyra'

Consejo Superior de Investigaciones Cientificas, Avd/Conocimiento

PT Ciencias de La Salud, ES-18100 Granada (Spain)

Tel. +34 958181 670, E-Mail elenag@ipb.csic.es 
compromise the viability of the organism, but an excessive response, due to a shortcoming in the deactivation mechanisms of the process, could cause acute or chronic inflammatory diseases $[2,3]$.

In these conditions, the immunostimulatory environment created by the release of cytokines could favor the recruitment and activation of professional antigen-presenting cells and autoreactive T cells. These $\mathrm{T}$ cells remain in the periphery as cells ignorant to self in normal conditions. However, if the inflammatory process is left unchecked, autoreactive T cells can become activated and fail to discriminate between self and non-self. As a consequence, loss of tolerance and the destruction of selftissues occur. This can cause a variety of chronic syndromes that Ehrlich termed 'horror autotoxicus' - now named autoimmune diseases [4].

Several autoimmune diseases resolve themselves, demonstrating the potential of the immune system to maintain tolerance to self-tissues through different mechanisms that operate at multiple and successive layers of regulation. For example, inflammatory responses are selfcontrolled by anti-inflammatory mediators secreted by the host's innate immune system during the ongoing process [5]. Moreover, the adaptive immune system also helps to maintain immune tolerance during infection-induced immunopathology [6]. There are different mechanisms for the intrinsic control of lymphocytes, including differentiation of T helper 2 cells (Th2) and central clonal deletion of self-reactive $\mathrm{T}$ cells in the thymus. Even if these self-reactive lymphocytes that escape central tolerance encounter their antigens, they may be inactivated in the periphery through the induction of anergy or by the action of regulatory $\mathrm{T}$ cells (Treg). These $\mathrm{T}$ cells have suppressive activity on immune responses, playing a critical role in immune homeostasis. Depletion of Treg cells in normal animals results in autoimmune disorders, and their reconstitution prevents disease. In fact, various autoimmune diseases (including multiple sclerosis, myasthenia gravis, rheumatoid arthritis, lupus erythematosus and type 1 diabetes) have shown defects in the function and number of Treg cells [6-8]. Moreover, the therapeutic use of antigen-specific Treg cells in models of autoimmune disorders has been demonstrated $[9,10]$.

Therefore, the success of the immune system is based on its ability to defend against foreign antigens and keep tolerance towards self. The appearance of inflammatory and autoimmune diseases reveals an imbalance in proinflammatory factors versus anti-inflammatory mediators, or, in self-reactive Th1/Th17 cells, versus Th2/Treg cells (fig. 1). From a therapeutic point of view, it is critical to identify agents able to regulate both components of the immune response: inflammation and autoimmunity.

As maintenance of immune tolerance is essential for survival, it is plausible to suppose that immune cells might produce endogenous factors during the inflammatory/autoimmune response in an attempt to keep it under control. Traditional anti-inflammatory and/or immunosuppressive cytokines have been the immediate candidates. In fact, treatments with anti-inflammatory cytokines, neutralizing antibodies for inflammatory cytokines, and agents preventing gene activation of inflammatory mediators - such as corticosteroids and non-steroidal anti-inflammatory drugs - have been used to block the immune response at different levels [11, 12]. However, the multistep nature of the inflammatory process has yielded controversial results. In the last decade, researchers have focused on investigating neuropeptides and hormones - classically considered as neuroendocrine mediators, but which are also produced by immune cells, especially under inflammatory conditions. Some of these neuropeptides have been included in the list of potential candidates to treat inflammatory and autoimmune disorders. In this review, we summarize the most recent data regarding the effects of endogenous neuropeptides on the regulation of the immune response, using the vasoactive intestinal peptide (VIP) as an example of immunomodulatory neuropeptides.

\section{Neuroendocrine and Immune Systems Talk to Each Other: Use of a Bidirectional and Common Language}

Restoration of immune homeostasis forms part of the corporal homeostatic equilibrium where there is a controlled balance between the physiological systems that modulate the internal environment of the organism. Considerable evidence indicates that an immune response is not solely determined by antigenic stimulation of an autonomous immune system. Relationships between the endocrine, nervous and immune systems are mediated by complex networks of primary and accessory cells and specific agents, which are in constant communication to develop a variety of coordinated responses to danger $[13,14]$. This biological dialogue implies that the immune system informs the neuroendocrine system when a systemic immune/inflammatory response to infection or tissue injury is occurring. The nervous system responds to this information with the orchestration of the febrile response and its subsequent effects on behavior, including sleep, mating, locomotion and feeding [15]. Conversely, the immune 
Fig. 1. The time course of the inflammatory response. Once the immune system is activated, different cell types and immune mediators are induced. After recognizing molecular patterns present in pathogens, the innate response provides the first line of defense, and induces the release of proinflammatory cytokines, chemokines and free radicals. Later, the adaptive response, which involves the activation of $\mathrm{T}$ and $\mathrm{B}$ lymphocytes, will lead to a memory being formed for a specific antigen. If the immune response is not controlled, it could lead to chronic inflammation, in which immune cells and molecules that respond to pathogen-derived antigens can also react to self-antigens. This immune autoreactivity together with a genetic predisposition and environmental factors could generate a variety of autoimmune diseases.

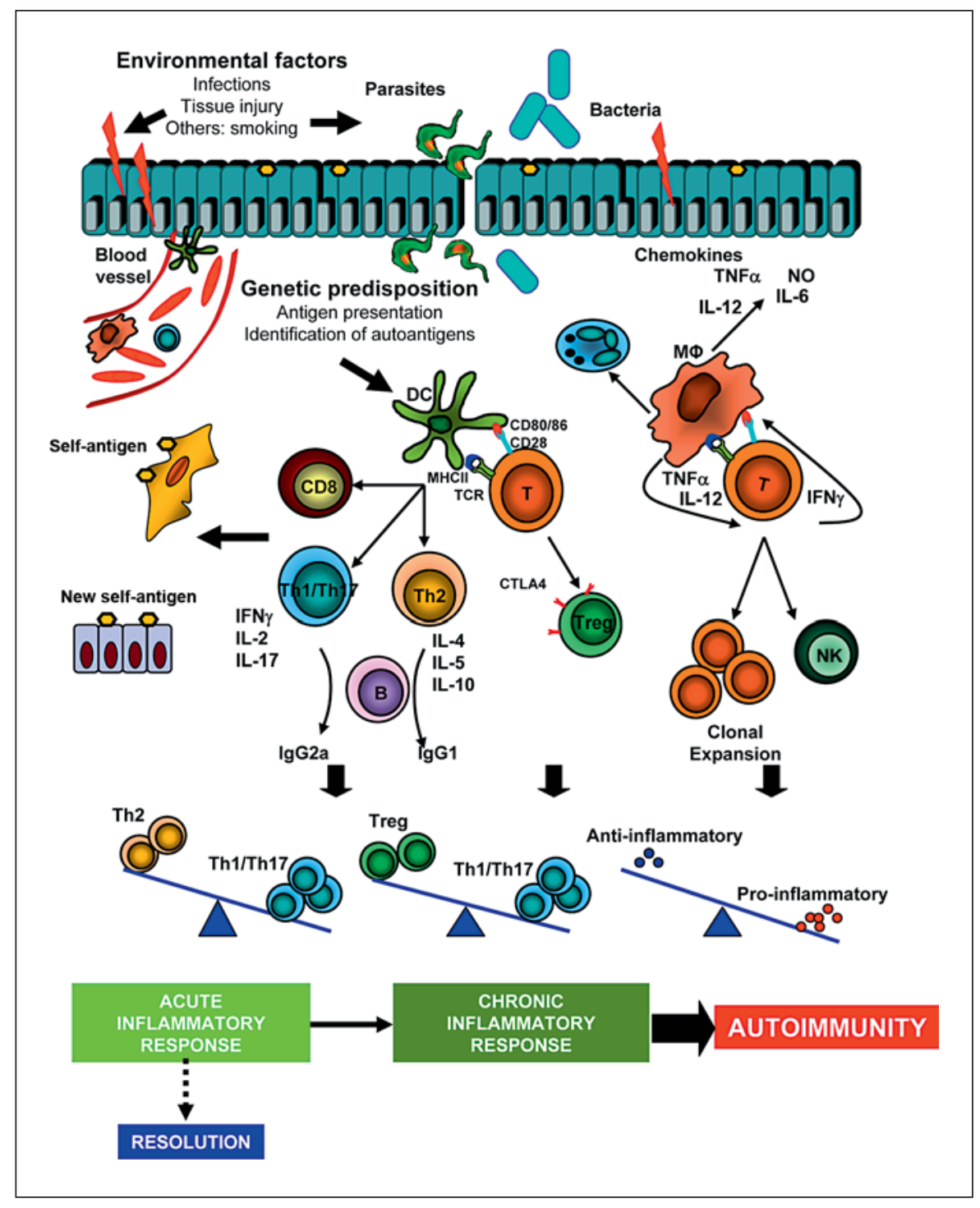

system is regulated by the nervous system. Both stress and immune stimuli activate various neuronal groups in the hypothalamus that trigger some important molecular pathways, in general anti-inflammatory and immunosuppressive, to limit the immune response. The activation of the hypothalamus-pituitary-adrenal axis and the secretion of glucocorticoids is the best example [13]. Besides corticoids, estrogens and catecholamines are also induced and released under these conditions. All of these are wellknown anti-inflammatory and immunosuppressive agents, widely used in clinics to harness the immune responses $[13,15]$. The antinociceptive and anti-inflammatory effect of opioids released during neurogenic inflammation is another example [16]. Furthermore, various neuropeptides are released at the peripheral endings of sensory and efferent nerves in close proximity to immune cells in response to various invasive and inflammatory stimuli. This interaction between immune and neuroendocrine systems is bidirectional, and is maintained through a mutual biochemical language, in which cytokines/interleukins produced by immune cells are recognized by receptors expressed on neuroendocrine cells, and, vice versa, cells of the immune system recognize neurotransmitters, neuropeptides and hormones produced by the nervous and endocrine systems. Interestingly, immune cells can also produce neuropeptides in response to antigenic and inflammatory signals, and these neuropeptides can act in an autocrine/paracrine manner through 
specific receptors expressed on immune cells [17-19]. Regarding neuropeptides with an immunomodulatory action, most show an anti-inflammatory profile, while fewer modulate the acquired immune response. Even more restricted is the number of neuropeptides with a prominent role in the regulation of immune tolerance. Here, we will focus on those neuropeptides known to dampen unwanted immune responses typical of inflammatory and autoimmune disorders.

\section{Endogenous Anti-Inflammatory Neuropeptides with an Immunomodulatory Role}

VIP, pituitary adenylate cyclase-activating polypeptide (PACAP), urocortin (UCN), adrenomedullin (AM), cortistatin (CST) and ghrelin (GHR) are neuropeptides produced by different cells and tissues and are associated with distinct physiological functions. Also, they belong to non-related families of peptides [20-24]. Although these neuropeptides look very different, they share certain characteristics that make them attractive for modulating immune tolerance: they are produced by immune cells, generally in response to inflammation, injury or antigen stimulation [25-27] (table 1); they bind to G-protein-coupled receptors expressed on different immunocompetent cells [28-30] (table 1); and these receptors are coupled to the activation of the cAMP/PKA pathway, which is related to downregulation of several transduction pathways associated with transcription of inflammatory mediators [31-33].

Studies with different experimental models have examined the role of these neuropeptides in inflammatory and autoimmune disorders. Treatment with VIP, PACAP, UCN, AM, CST or GHR delays the onset, increases survival and reduces the severity of various experimental models of sepsis [34-38], collagen-induced arthritis [3942], inflammatory bowel disease [43-46], multiple sclerosis [47-49], type I diabetes mellitus [50], Sjögren's syndrome [51], pancreatitis [52, 53] and uveoretinitis [54, 55] (table 1). The therapeutic effect of these neuropeptides is associated with the reduction of the two main phases of these diseases. They downregulate early events that are associated with the initiation and establishment of autoimmunity to self-tissue components, as well as later phases that are associated with the evolving immune and destructive inflammatory responses. These neuropeptides impair the development of self-reactive Th1 cells, their entry into the target organ, the release of inflammatory cytokines and chemokines, and the subsequent recruit- ment and activation of macrophages and neutrophils. This results in a decreased production of destructive inflammatory mediators (cytokines, nitric/oxygen radicals and matrix metalloproteinases) by infiltrating and resident inflammatory cells. Most data coming from studies using VIP have demonstrated that the mechanisms involved in the suppressive effects of the neuropeptides include the regulation of various levels of the immune response (fig. 2).

Regarding innate immunity, VIP, PACAP, AM, UCN, CST and GHR reduce the production of inflammatory cytokines and chemokines while stimulating the production of anti-inflammatory cytokines such as IL-10 and IL-1Ra $[25,30,34,35,43,44,56,57]$ (see table 1 for specific effects). VIP, PACAP, UCN and CST also downregulate the expression of other inflammatory mediators, such as inducible nitric oxide synthase and cyclooxygenase 2 (COX2), and the subsequent release of nitric oxide and prostaglandin E2 by macrophages, dendritic cells (DCs) and microglia [58-61]. Specifically, VIP and GHR regulate the activation of peritoneal macrophages, by inhibiting their phagocytic activity, and modulate free radical production, adherence and migration $[62,63]$. In the same way, VIP and UCN induce apoptosis of macrophages under inflammatory conditions which affects its subsequent activation $[62,64]$.

Recent studies have shown that VIP, GHR and UCN reduce the secretion of the critical factor high-mobility group box-1, which is a late mediator of inflammation that also plays an important role in autoimmunity $[65,66]$.

Neuropeptides also modulate inflammatory responses through the regulation of different functions of mast cells, such as degranulation [38, 67-69].

On the other hand, AM and GHR induce the peroxisome proliferator-activated receptor- $\gamma$, a transcription factor that plays a critical role in the regulation of inflammation [70, 71].

At the level of adaptive immunity, most data coming from VIP studies show that neuropeptides may regulate the Th1/Th2/Treg balance through different non-exclusive mechanisms (table 1). Thus, they directly reduce the proliferation of activated Th1 cells, inhibit the production of the Th1-associated cytokines IL-2, IFN and IL-17, and impair the recruitment of Th1 cells by inhibiting the secretion of specific chemokines [40-46, 72, 73]. Recent in vivo studies have shown that VIP, UCN, AM and CST reduce the presence of Th17 cells in inflamed tissues and lymph nodes [40-43, 46, 49]. However, it is not clear whether this effect is a consequence of reduced infiltra- 
Table 1. Neuropeptides with immunomodulatory actions: immune source, receptors, functions and therapeutic effects

\begin{tabular}{|c|c|c|c|c|}
\hline Neuropeptide & $\begin{array}{l}\text { Immune } \\
\text { source }^{\mathrm{a}}\end{array}$ & Receptor: immune cell ${ }^{\mathrm{b}}$ & Immune function $^{c}$ & $\begin{array}{l}\text { Therapeutic } \\
\text { effects }^{\mathrm{d}}\end{array}$ \\
\hline VIP/PACAP & $\begin{array}{l}\text { CD4 Th2, } \\
\text { CD8 T2, } \\
\text { PMNC, } \\
\text { mast cells }\end{array}$ & $\begin{array}{l}\text { VPAC1: T, M } \phi, M o, D C, \text { PMNC } \\
\text { VPAC2: T, M } \phi \text { (inducible) } \\
\text { PAC1: M } \phi, \text { Mo }\end{array}$ & $\begin{array}{l}\downarrow \text { inflammatory cytokines } \\
\downarrow \text { chemokines } \\
\downarrow \text { costimulation macrophages and DCs } \\
\uparrow \text { IL-10, TGF- } \beta \\
\downarrow \text { T cell proliferation } \\
\downarrow \text { Th1 response: IL- } 2 \text { and IFN- } \gamma \text { production, and differentiation } \\
\downarrow \text { Th1 recruitment } \\
\downarrow \text { Th2 apoptosis } \\
\downarrow \text { Th2 response and recruitment } \\
\uparrow \text { Treg cells } \\
\uparrow \text { generation tolerogenic DCs } \\
\uparrow \text { IgA production by B cells }\end{array}$ & $\begin{array}{l}\text { sepsis } \\
\text { pancreatitis } \\
\text { RA } \\
\text { EAE } \\
\text { EAU } \\
\text { IBD } \\
\text { T1DM } \\
\text { SD }\end{array}$ \\
\hline UCN & $\begin{array}{l}\mathrm{T}, \mathrm{B}, \\
\mathrm{M} \phi, \text { Mo, } \\
\text { mast cells }\end{array}$ & CRFR2: T, M $\phi$, Mo, DC, PMNC & $\begin{array}{l}\downarrow \text { inflammatory factors } \\
\downarrow \text { chemokines } \\
\uparrow \text { IL-10/TGF- } \beta 1 \text { production } \\
\downarrow \text { T cell proliferation } \\
\downarrow \text { Th1 response: IL- } 2 \text { and IFN- } \gamma \\
\uparrow \text { Treg cells }\end{array}$ & $\begin{array}{l}\text { sepsis } \\
\text { IBD } \\
\text { RA } \\
\text { EAE }\end{array}$ \\
\hline $\mathrm{AM}$ & $\mathrm{M \phi}, \mathrm{Mo}$ & CRLR-RAMP2/3: T, M $\phi$, Mo, DC & $\begin{array}{l}\downarrow \text { inflammatory factors } \\
\downarrow \text { chemokines } \\
\uparrow \text { IL-10/TGF- } \beta \text { production } \\
\downarrow \text { T cell proliferation } \\
\downarrow \text { Th1 response: IL- } 2 \text { and IFN- } \gamma \\
\uparrow \text { Treg cells }\end{array}$ & $\begin{array}{l}\text { sepsis } \\
\text { IBD } \\
\text { RA }\end{array}$ \\
\hline CST & $\mathrm{T}, \mathrm{Mo}, \mathrm{M} \phi$ & $\begin{array}{l}\text { SST1-5: T, M } \phi, M o, D C \\
\text { GHSR: T, M } \phi \text {, Mo }\end{array}$ & $\begin{array}{l}\downarrow \text { inflammatory factors } \\
\downarrow \text { chemokines } \\
\uparrow \text { IL-10/TGF- } \beta 1 \text { production } \\
\downarrow \text { T cell proliferation } \\
\downarrow \text { Th1 response/differentiation } \\
\uparrow \text { Treg cells }\end{array}$ & $\begin{array}{l}\text { sepsis } \\
\text { RA } \\
\text { IBD }\end{array}$ \\
\hline GHR & Mo, Mф & GHSR: T, M $\phi$, Mo, DC & $\begin{array}{l}\downarrow \text { inflammatory cytokines } \\
\downarrow \text { chemokines } \\
\uparrow \text { IL- } 10 / \text { TGF- } \beta 1 \text { production } \\
\downarrow \text { T cell proliferation } \\
\downarrow \text { Th1 response: IL- } 2 \text { and IFN- } \gamma \text { production } \\
\uparrow \text { Treg cells }\end{array}$ & $\begin{array}{l}\text { sepsis } \\
\text { EAE } \\
\text { IBD } \\
\text { RA }\end{array}$ \\
\hline $\begin{array}{l}\text { SST1-5 = } \\
\text { CRLR = calcit } \\
\text { cortistatin; VP } \\
\text { vasoactive int } \\
\text { PACAP = pitu } \\
\text { ceptor-activity } \\
\text { monocyte; DC } \\
\text { cell; EAE }=\text { ex }\end{array}$ & $\begin{array}{l}\text { omatostatin } \\
\text { hin-related lig } \\
\mathrm{C}=\mathrm{VIP} / \mathrm{PAC} \\
\text { tinal peptide } \\
\text { ary adenylate } \\
\text { modifying pr } \\
=\text { dendritic ce } \\
\text { erimental aut }\end{array}$ & $\begin{array}{l}\text { eptors } 1-5 ; \text { GHSR }=\text { ghrelin rece } \\
\text { receptor; CRFR = CRH receptor; } \mathrm{C} \\
\text { receptor; PAC = PACAP receptor; } \mathrm{V} \\
\mathrm{A}=\text { adrenomedullin; } \mathrm{UCN}=\text { uroco } \\
\text { ase-activating polypeptide; } \mathrm{RAMP} \\
\text { as; } \mathrm{T}=\mathrm{T} \text { cell; } \mathrm{M} \phi=\text { macrophage; } \mathrm{N} \\
\mathrm{MNC}=\text { polymorphonuclear cell; } \mathrm{B} \\
\text { mune encephalomyelitis; } \mathrm{RA}=\text { rheu }\end{array}$ & \multicolumn{2}{|c|}{$\begin{array}{l}\text { toid arthritis; EAU = experimental autoimmune uveitis; } \mathrm{IBD}=\text { inflamma- } \\
\text { tory bowel disease; T1DM = type } 1 \text { diabetes mellitus; } \mathrm{SD}=\text { Sjögren's dis- } \\
\text { ease; Th }=\mathrm{T} \text { helper cell. } \\
{ }^{\mathrm{a}} \text { Immune cells producing neuropeptides. } \\
\text { neuropeptide receptor subtypes. }{ }^{\mathrm{c}} \text { Major roles of the neuropeptides related } \\
\text { with autoimmune response. }{ }^{\mathrm{d}} \text { Beneficial effects of neuropeptides in various } \\
\text { experimental models of inflammation and autoimmunity. } \uparrow=\text { Stimulation; } \\
\downarrow=\text { inhibition. }\end{array}$} \\
\hline
\end{tabular}

tion of immune cells, or a direct effect of Th17 differentiation and/or migration. The action of neuropeptides on the responses mediated by Th17 cells needs to be further investigated.

The inhibition of self-reactive Thl cell responses affects B cells indirectly as it results in decreased levels of autoantibodies (especially IgG2a antibodies) [22, 23, 25-
$27,34]$. This could contribute to the amelioration of the destructive responses on the target tissue because this isotype of antibodies is involved in complement and neutrophil activation. Recent reports have also demonstrated that VIP acts directly on the mucosal immune system where it increases the synthesis of IgA, suggesting a critical role for VIP in the induction of oral tolerance [74]. 
Fig. 2. Mechanisms involved in the immunomodulatory effect of neuropeptides. VIP, AM, UCN, CST and GHR are released in the context of an immune response from different sources: nerves terminals, lymphocytes (mainly Th2 CD4 and T2 CD8 cells) and blood. Together with the recently discovered bactericidal and trypanolytic effect, these neuropeptides have an immunomodulatory role. They impair the inflammatory response by inhibiting the production of inflammatory mediators and by inducing the production of anti-inflammatory cytokines. In addition, they decrease the co-stimulatory activity of antigen-presenting cells on effector $\mathrm{T}$ cells, inhibiting subsequent clonal expansion. Moreover, neuropeptides regulate the balance between Th1/ Th17/Th2 and Treg cells. As a consequence, the effects of the neuropeptides on the innate and adaptive immune responses result in diminished inflammation and organ-specific autoimmunity, avoid undesired immunopathologies resulting from infection, and restore immune tolerance. Red lines indicate inhibition. Blue dashed lines indicate positive stimulation. CTLA4 = Cytotoxic T-lymphocyte-associated protein 4 ; TCR $=\mathrm{T}$ cell receptor.

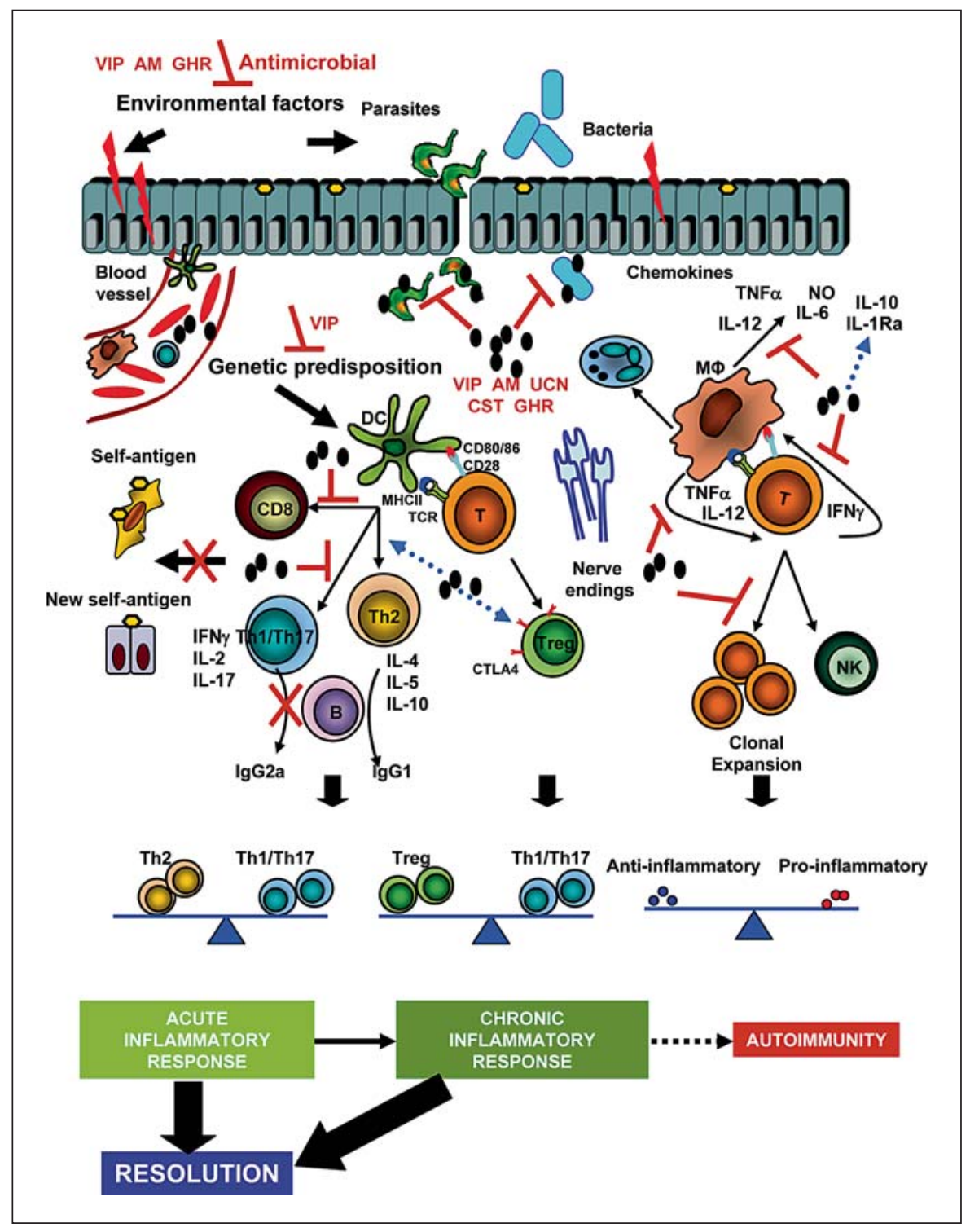

On the other hand, considerable evidence indicates that the generation of Treg cells plays a major role in the beneficial effect of these neuropeptides in autoimmunity [4042 , 46, 75-77]. VIP, UCN, CST, AM and GHR induce the peripheral expansion of new antigen-specific CD4+ CD25+ Treg cells that express forkhead box P3 (FOXP3)+, a master gene of Treg cells. The suppression of self-reactive effector T cells by the Treg cells generated by these neuropeptides suppress self-reactive effector $\mathrm{T}$ cells through a mechanism that depends on direct cellular contacts and on the expression of immunosuppressive mediators such as the cytotoxic T-lymphocyte-associated protein 4 (CTLA4) and the cytokines IL-10 and/or TGF- $\beta$ [75-77].
In addition, VIP induces the differentiation of tolerogenic DCs (tolDCs) from bone marrow precursors or monocytes [78-80]. The VIP-induced tolDCs have the ability to generate antigen-specific Treg cells with suppressive actions on effector $\mathrm{T}$ cells and to transfer antigen-specific tolerance in vivo.

Taken together, these results indicate that neuropeptides can target a wide spectrum of inflammatory mediators, regulating the immune response at different levels. This is probably the most relevant advantage of neuropeptide treatment over current therapies. The key to the potent spectrum of action of these neuropeptides is their high-affinity binding to specific receptors that are cou- 


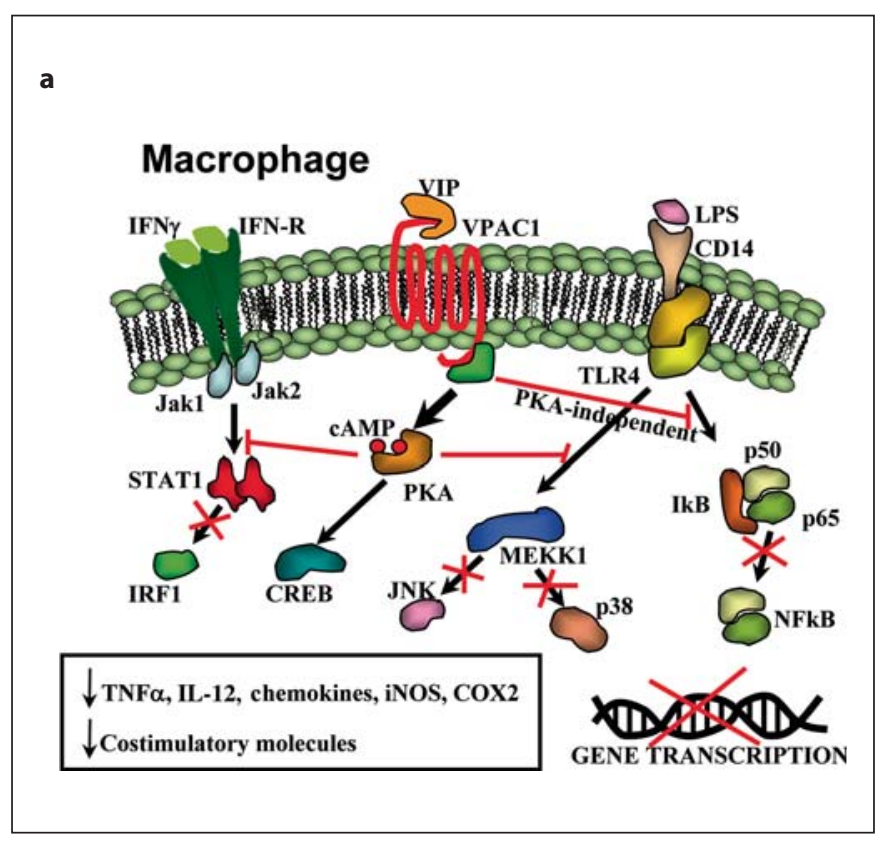

Fig. 3. Molecular mechanisms and transcription factors involved in the VIP signaling in immune cells. a VIP signaling during inflammatory response (macrophage, microglia and DCs). Binding of VIP to VPAC1 induces CAMP and activates PKA, and exerts several effects: (1) inhibition of IFN- $\gamma$-induced Jak1/Jak2 phosphorylation, STAT1 activation and binding of IRF1 to promoters of inflammatory genes; (2) inhibition of various mitogen-activated protein kinase (MAPK) cascades, and subsequent inhibition of Jun kinase (JNK) and p38 MAPK activities; (3) stimulation of cAMP-responsive element binding (CREB) factor to compete with NFKB for coactivators. Moreover, through a PKA-independent mechanism, VIP-VPAC1 interaction inhibits IкB-kinase activity and suppresses nuclear translocation and activation of the transcription factor NFкB. All these pathways act in concert to activate gene transcription of most inflammatory mediators. LPS = Bacterial lipopolysaccharide. $\mathbf{b}$ VIP signaling on T lymphocytes. VIP binding to VPAC (mainly VPAC1) increases

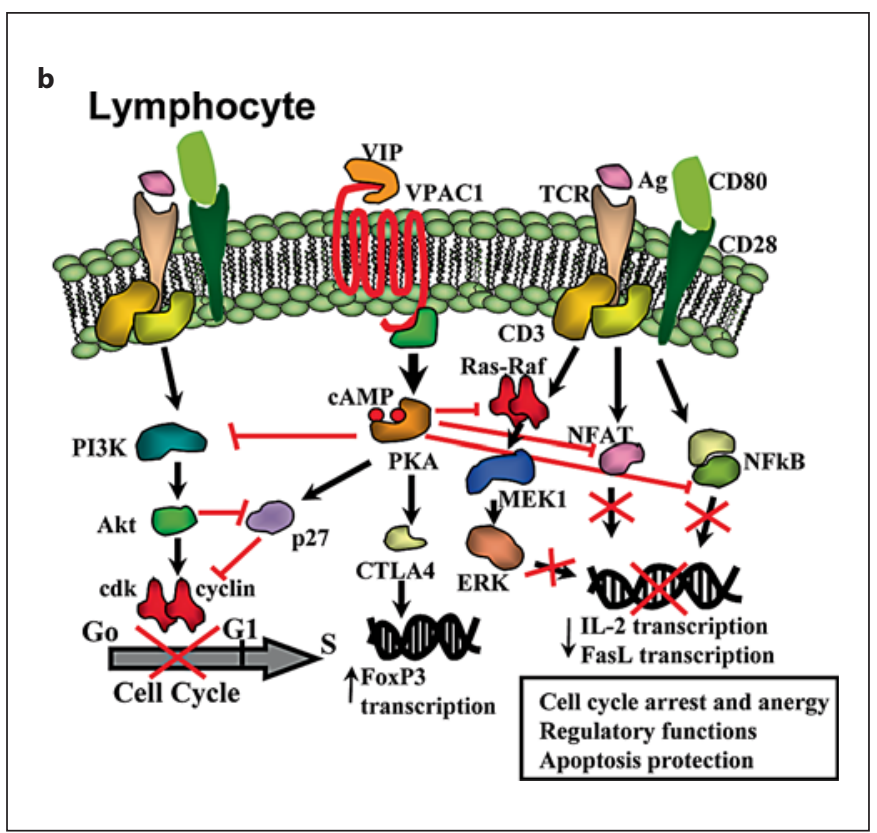

cAMP and activates PKA, which could regulate $\mathrm{T}$ cell cycle and activation at multiple levels: (1) VIP downregulates the PI3K-Akt pathway, and consequently, the activity of different cdk-cyclin complexes, affecting DNA replication and progression through S phase of cell cycle; (2) VIP also increases the levels of the cdkinhibitor p $27^{\mathrm{kipl}}$ which binds/inactivates the cyclin E-cdk 2 complexes resulting in arrest of the cell in G1 phase; (3) VIP inhibits signaling through the Ras-Raf1-MEK1-ERK1 and decreases the nuclear translocation of NFKB and NFAT, all required for IL-2 transcription; (4) VIP increases the expression of both soluble and membrane forms of CTLA4, which are critically involved in the induction of transcription factor FoxP3 and in the regulatory/ suppressive activity of the VIP-treated T cells. Finally, by decreasing NFAT and NFкB signaling, VIP inhibits FasL expression in activated $\mathrm{T}$ cells and subsequent apoptosis induced by FasL-Fas interaction. Red-crossed black arrows represent inhibitory signals. pled to the cAMP-PKA pathway (fig. 3). Activation of this intracellular pathway leads to the downregulation of most of the transcription factors involved in the gene expression of inflammatory cytokines, chemokines and costimulatory factors, including nuclear factor- $\kappa \mathrm{B}$, mitogen-activated protein kinases, interferon regulatory factor 1 and activator protein $1[17,25,31-33]$. Recent reports have also indicated that neuropeptides such as VIP and PACAP could also affect common upstream elements located in the early stages of these signaling pathways, such as inhibition of the expression of Toll-like receptors and associated proteins (i.e. endotoxin binding factor CD14) $[81,82]$. Although most of these findings have been re- ported for VIP, studies in other cell types have demonstrated that UCN, AM and GHR regulate several of the pathways described, suggesting that they could also be involved in their immunosuppressive effects. Further experiments will determine whether the regulation of these pathways by neuropeptides could be extended to other cells participating in the inflammatory response, such as DCs or polymorphonuclear cells. The differential expression and signaling of these receptors in immune cells, their dimerization with other receptors and their association with certain receptor-activity-modifying proteins have also shed light on the existing controversy about the emergence of new anti-inflammatory neuropeptides, 
such as UCN, AM and CST, which show more potent, and in some cases opposite, actions on immune tolerance compared with their respective structurally related peptides (corticotrophin-releasing hormone, calcitonin gene-related peptide and somatostatin).

\section{Functional Neuropeptide Network Is Crucial for Maintaining a Healthy State}

In view of this plethora of actions mediated by some neuropeptides, an important issue relates to the physiological role played by endogenous neuropeptides in the maintenance of immune homeostasis. Animals deficient in one of these neuropeptides or their receptors have highlighted the relevance of alterations in their endogenous levels and their association with the onset of certain autoimmune and inflammatory processes. The deficiency of VIP, AM, VIP/PACAP receptors or UCN results in higher susceptibility to endotoxemia, lung inflammation and Th1-mediated responses in vivo [83, 84]. Low endogenous levels of GHR in endotoxemia, arthritis and infection with Helicobacter pylori increased the inflammatory damage caused in each of these diseases $[85,86]$. Recently, the results obtained with PACAP-KO mice have supported these findings in an autoimmune environment. PACAP-KO mice show higher incidence and severity of experimental autoimmune encephalomyelitis (EAE), increased inflammatory and Th1-encephalitogenic cells, and decreased antigen-specific Treg cells [87]. Interestingly, the response of VIP-KO mice to EAE results in a delayed onset and mild clinical profile [88]. Although VIP-KO mice exhibited robust Th1/Th17 cell inductions and cytokine responses, showing their increased EAE profile, VIP loss seemed to be involved in the immune infiltration of the nervous parenchyma. Other studies have described that mice deficient in GHR/GHSR have reduced thymic output, increased thymic adiposity and alterations in the thymic stromal environment [89]. This could affect the generation and selection of the different $\mathrm{T}$ cell subsets.

Regarding human conditions, patients with arthritis, endotoxemia, gastritis and ulcerative colitis have elevated levels of UCN and AM. Brain samples from patients with degenerative disorders, such as Parkinson or Alzheimer, show low levels of VIP $[90,91]$. Also, VIP levels are reduced in patients with lupus and autoimmune thyroiditis, where there are significant levels of VIP autoantibodies [92]. Recent studies have shown that monocytes, synoviocytes and $\mathrm{T}$ cells isolated from patients with rheumatoid arthritis, osteoarthritis and multiple sclerosis express less
VIP receptors, and consequently respond less to VIP, than cells from healthy subjects [93-95]. This altered expression of VIP receptors seems to be related to an aberrant autoreactive Th1-driven inflammatory response in these patients, and it is genetically associated with a functional polymorphism in rheumatoid arthritis and spondylitis [94]. Taken together, these results suggest that a healthy neuropeptide system is needed, as neuropeptides are intrinsic modulators of the immune response, and that a failure in the neuropeptide/receptor signaling system affects the maintenance of immune homeostasis.

\section{Neuropeptides Are Not Immunosuppressive Agents}

If the main actions of these peptides in the immune system are directed towards deactivating the immune response, one potential risk of their being used is a generalized immunosuppressive effect and a compromised response to infections. However, contrary to the expected results, septic mice treated with these peptides had lower peritoneal bacterial counts than untreated mice. Interestingly, it has been shown by ourselves and others that some of these neuropeptides, such as AM and GHR, are able to exert a direct antibacterial effect [66, 96-98]. This is especially important in some autoimmune conditions such as Crohn's disease, where the imbalance between commensal and pathogenic bacteria could be one of the initiators of the autoimmune response against the bowel components. Interestingly, neuropeptides are present in primitive organisms and are highly conserved throughout evolution. They are mainly produced by epithelial and mucosal surfaces under inflammatory conditions, and show an amino acid composition, amphipathic design and cationic charge. These characteristics resemble natural antimicrobial peptides (i.e. defensins) that mainly seem to form pores on the plasma membrane of the bacteria (negatively charged) leading to osmotic instability and cell death. Importantly, all these neuropeptides also showed significant antiparasitic actions against protozoa parasites (also showing a highly negatively charged coat). Neuropeptides specifically kill the bloodstream forms of Trypanosoma brucei, the causative agent of sleeping sickness, using a non-traditional mode of action [99]. This involves peptide uptake and accumulation into intracellular vesicles, disruption of lysosome integrity and energetic metabolism failure that initiates an autophagic-like cell death. Interestingly, fragments of neuropeptides (i.e. VIP 6-28), produced by polymorphonuclear cells and unable to signal in mammal cells, show parasiticidal activity [99]. From a 
therapeutic point of view, targeting intracellular compartments by neuropeptides proposes a new promising strategy for the treatment of parasitic diseases that overcomes resistance. These results are also relevant for some autoimmune myocardial disorders associated with other trypanosomatids, such as Trypanosoma cruzi. Of physiological importance is the fact that the hosts respond to trypanosome infection by producing neuropeptides as part of their natural innate defense [99].

\section{Are Neuropeptides Ready for the Clinic? Advantages versus Pitfalls}

The immunomodulatory and pleiotropic actions of neuropeptides in the control of autoimmune/inflammatory and infectious diseases should provide insight into therapeutic approaches. However, as with most studies that use animal models, precautions should be taken when considering human diseases. The potential side effects derived from the general actions of these neuropeptides in the body should be considered, such as hypotension, decreased gut motility and diarrhea. It is important to note that some of these neuropeptides have already been administered systemically and locally to humans for the treatment of specific immune disorders, without such complications $[100,101]$. In contrast to existing antiinflammatory drugs, neuropeptides are not associated with dramatic side effects because, being physiological compounds, they are intrinsically nontoxic. Neuropeptides are small and hydrophilic molecules, which enable rapid access to the site of inflammation, and they are rapidly cleared from the body through natural hepatic detoxification mechanisms and renal excretion. Moreover, other cytokines, neuropeptides and hormones often counterbalance their actions, and the homeostasis of normal tissues is not perturbed. Despite these advantages, several obstacles remain to the translation of neuropeptide-based treatment into viable clinical therapies. Due to their nature as peptides, they are highly unstable and extremely sensitive to peptidases present in most tissues. Therefore, pharmaceutical companies are currently focusing on the development of metabolically stable analogs. However, in the case of the type 2 G-protein-coupled receptors (i.e. receptors for VIP, UCN and AM), the pharmaceutical industry has so far failed to generate effective specific non-peptide agonists [102]. Understanding the structure-function relationship of these neuropeptides and their specific receptors - including receptor signaling, internalization, and homo- and heterodimerization in physiological and pathologic situations - will facilitate the development of novel pharmacological agents. Meanwhile, we should focus on developing new strategies to allow the direct use of natural peptides, increasing neuropeptide half-life and improving their targeted tissue delivery, especially in long-term treatments [for a review, see 103]. For example, modifications in the sequence or cycling of the structure increase the stability of these peptides. Improving neuropeptide delivery to target tissues and cells while protecting them against degradation includes strategies based on neuropeptide gene delivery, the insertion into micelles or nanoparticles, or combining neuropeptide treatment with endopeptidase inhibitors. Alternatively, administration of serum-specific neuropeptide-binding proteins might protect them from peptidases and enhance their delivery in the proximity of their receptors in the inflamed tissue. Finally, other combined treatments aim to take advantage of the knowledge that activation of the $\mathrm{cAMP} /$ protein kinase A pathway appears to be the major signal involved in the immunomodulatory effect of these neuropeptides. Thus, combining neuropeptides with inhibitors of phosphodiesterases (enzymes involved in the degradation of cAMP) has been found to be therapeutically attractive in the treatment of some immune disorders.

Beside their use as drugs, neuropeptides could be used in a second potential translational strategy by inducing the expansion and/or generation of Treg cells in vivo or ex vivo, or through the capacity of neuropeptide-induced tolDCs pulsed with self-antigens to induce antigenspecific Treg cells [8]. One of the most important issues that needs to be solved for this cell-based therapy is to identify the antigen specificity in various autoimmune disorders. Whereas polyclonal Treg cells might function in allograft transplantation and in autoimmunity in lymphopenic (i.e. systemic lupus erythematosus) or inflammatory bowel diseases, in other autoimmune disorders, antigen-specific Treg cells are most effective [8]. In addition, this individualized cell-based therapy will require ex vivo manipulation of the blood cells of patients. Therefore, it is urgent to determine whether the neuropeptideinduced Treg cells or tolDCs ex vivo show the same suppressive efficacy, reliability, homing capacity and survival in vivo compared to those obtained from animals or healthy individuals, since there is considerable variability between patients.

Collectively, the findings described here show the tremendous plasticity of these neuropeptides for the clinical translation to human immune and/or infectious disorders. 


\section{Conclusions}

Organisms fight against diverse pathogens with the aid of a highly diverse immune system, which needs to be well coordinated at all times as an imbalance in the immune response could induce inflammatory and autoimmune disorders. In recent years, research in the field of neuropeptides has shown that the production of these endogenous anti-inflammatory factors increases when an exacerbated inflammatory response is present. The basic findings described here show the essential role of these endogenous molecules in restoring immune homeostasis and in the development of mechanisms for self-tolerance, which is a fundamental property of the vertebrate immune system. In addition, neuropeptides have also shown antimicrobial and antiparasitic actions, which is noteworthy from an evolutionary point of view, because these neuropeptides appear early, i.e. in very primitive organisms with very simple nervous and immune systems even before their specific receptors are present. These re- sults suggest that perhaps the primeval role of neuropeptides was closely related to the natural immune defense as antimicrobial peptides coevolved with the pathogens and acquired additional functions during evolution. Based on their immunomodulatory and pleiotropic effects, neuropeptides could have participated in a dynamic evolution in which non-traditional immune components facilitated the homeostatic cross-talk between the innate and adaptive immune systems - thus limiting inflammatory/autoimmune disorders (fig. 2). Considering these characteristics, neuropeptides represent a feasible therapeutic agent for the treatment of human immune diseases with both inflammatory and autoimmune components.

\section{Acknowledgements}

This work has been supported by the Spanish Ministry of Science and Innovation and Junta de Andalucía.

\section{References}

1 Janeway Jr CA, Medzhitov R: Innate immune recognition. Annu Rev Immunol 2002; 20 : 197-216.

-2 Ebong S, Call D, Nemzek J, Bolgos G, Newcomb D, Remick D: Immunopathologic alteration in murine models of sepsis of increasing severity. Infect Immun 1999; 67: 6603-6610.

-3 Stallmach A, Strober W, MacDonald TT, Lochs $\mathrm{H}$, Zeitz M: Induction and modulation of gastrointestinal inflammation. Immunol Today 1998; 19: 438-441.

$\checkmark 4$ Goodnow CC: Multistep pathogenesis of autoimmune diseases. Cell 2007; 130: 25-35.

$\checkmark 5$ Nathan C: Points of control in inflammation. Nature 2002: 420: 846-852.

$\checkmark 6$ Mills KHG: Regulatory T cells: friend or foe in immunity to infection? Nat Rev Immunol 2004; 4: 841-855.

7 Shevach EM: From vanilla to 28 flavors: multiple varieties of $\mathrm{T}$ regulatory cells. Immunity 2006; 25: 195-201.

$\checkmark 8$ Bluestone JA: Regulatory T-cell therapy: is it ready for the clinic? Nat Rev Immunol 2005; 5: 343-349.

$\checkmark 9$ Lindley S, Dayan CM, Bishop A, Roep BO, Peakman M, Tree TI: Defective suppressor function in CD4+CD25+ T-cells from patients with type 1 diabetes. Diabetes 2005; 54 : 92-99.

$>10$ Viglietta V, Baecher-Allan C, Weiner HL, Hafler DA: Loss of functional suppression by CD4+CD25+ regulatory $\mathrm{T}$ cells in patients with multiple sclerosis. J Exp Med 2004; 199 : 971-979.
Geissler K: Current status of clinical development of interleukin-10. Curr Opin Hematol 1996; 3: 203-208.

12 Cain BS, Meldrum DR, Harken AH, McIntyre RC: The physiologic basis for anticytokine clinical trials in the treatment of sepsis. J Am Coll Surg 1998; 186: 337-350.

13 Sternberg EM: Neural regulation of innate immunity: a coordinated nonspecific host response to pathogens. Nat Rev Immunol 2006 6: 318-328.

14 Elenkov IJ, Wilder RL, Chrousos GP, Vizi S: The sympathetic nerve - an integrative interface between two supersystems: the brain and the immune system. Pharmacol Rev 2000; 52: 595-638.

15 Blalock JE: The immune system as the sixth sense. J Intern Med 2005; 257: 126-138.

16 Molina PE: Opioids and opiates: analgesia with cardiovascular, haemodynamic and immune implications in critical illness. J Intern Med 2006; 259: 138-154.

17 Gonzalez-Rey E, Delgado M: Anti-inflammatory neuropeptide receptors: new therapeutic targets for immune disorders? Trends Pharmacol Sci 2007; 28: 482-491.

18 Lühder F, Lee DH, Gold R, Stegbauer J, Linker RA: Small but powerful: short peptide hormones and their role in autoimmune inflammation. J Neuroimmunol 2009; 217: 1-7.

19 Gonzalez-Rey E, Chorny A, Delgado M: Regulation of immune tolerance by anti-inflammatory neuropeptides. Nat Rev Immunol 2007; 7: 52-63.
20 Said SI, Mutt V: Polypeptide with broad biological activity: isolation from small intestine. Science 1970; 169: 1217-1218.

21 Oki Y, Sasano H: Localization and physiological roles of urocortin. Peptides 2004; 25: 1745-1749.

22 Hinson JP, Kapas S, Smith DM: Adrenomedullin, a multifunctional regulatory peptide. Endocr Rev 2000; 21: 138-167.

23 Spier AD, De Lecea L: Cortistatin: a member of the somatostatin neuropeptide family with distinct physiological functions. Brain Res Rev 2000; 33: 228-241.

24 Van der Lely AJ, Tschop M, Heiman ML, Ghigo E: Biological, physiological, pathophysiological, and pharmacological aspects of ghrelin. Endocr Rev 2004; 25: 426-457.

$\checkmark 25$ Delgado M, Pozo D, Ganea D: The significance of vasoactive intestinal peptide in immunomodulation. Pharmacol Rev 2004; 56: 249-290.

26 Kubo A, Minamino N, Isumi Y, Katafuchi T, Kangawa K, Dohi K, Matsuo H: Production of adrenomedullin in macrophage cell line and peritoneal macrophage. J Biol Chem 1998; 273: 16730-16738.

27 Dalm VA: Cortistatin rather than somatostatin as a potential endogenous ligand for somatostatin receptors in the human immune system. J Clin Endocrinol Metab 2003; 88: 270-276.

28 Gonzalez-Rey E, Delgado M: Anti-inflammatory neuropeptide receptors: new therapeutic targets for immune disorders? Trends Pharmacol Sci 2007; 28: 482-491. 
29 Dalm VA: Expression of somatostatin, cortistatin, and somatostatin receptors in human monocytes, macrophages, and dendritic cells. Am J Physiol Endocrinol Metab 2003; 285:E344-E353.

-30 Dixit VD, Schaffer EM, Pyle RS, Collins GD, Sakthivel SK, Palaniappan R, Lillard JW Jr, Taub DD: Ghrelin inhibits leptin and activation-induced proinflammatory cytokine expression by human monocytes and T cells. J Clin Invest 2004; 114: 57-66.

>31 Poyner DR, Sexton PM, Marshall I, Smith DM, Quirion R, Born W, Muff R, Fischer JA, Foord SM: International Union of Pharmacology. XXXII. The mammalian calcitonin gene-related peptides, adrenomedullin, amylin, and calcitonin receptors. Pharmacol Rev 2002; 54: 233-246.

>32 Hauger RL, Grigoriadis DE, Dallman MF, Plotsky PM, Vale WW, Dautzenberg FM: International union of pharmacology. XXXVI. Current status of the nomenclature for receptors for corticotropin-releasing factor and their ligands. Pharmacol Rev 2003; 55: 21-26.

-33 Harmar AJ, Arimura A, Gozes I, Journot L, Laburthe M, Pisegna JR, Rawlings SR, Robberecht P, Said SI, Sreedharan SP, Wank SA, Waschek JA: International Union of Pharmacology. XVIII. Nomenclature of receptors for vasoactive intestinal peptide and pituitary adenylate cyclase-activating polypeptide. Pharmacol Rev 1998; 50: 265-270.

34 Gonzalez-Rey E, Chorny A, Varela N, Robledo G, Delgado M: Urocortin and adrenomedullin prevent lethal endotoxemia by downregulating the inflammatory response. Am J Pathol 2006; 168: 1921-1930.

>35 Gonzalez-Rey E, Chorny A, Robledo G, Delgado $\mathrm{M}$ : Cortistatin, a new anti-inflammatory peptide with therapeutic action in lethal endotoxemia. J Exp Med 2006; 203: 463-471.

\$6 Delgado M, Martinez C, Pozo D, Calvo JR, Leceta J, Ganea D, Gomariz RP: Vasoactive intestinal peptide (VIP) and pituitary adenylate cyclase-activating polypeptide (PACAP) protect mice from lethal endotoxemia through the inhibition of TNF- $\alpha$ and IL-6. J Immunol 1999; 162: 1200-1205.

>37 Wu R: Ghrelin improves tissue perfusion in severe sepsis via downregulation of endothelin-1. Cardiovasc Res 2005; 68: 318-326.

$>38$ Tuncel N, Tore F, Sahinturk V, Ak D, Tuncel M: Vasoactive intestinal peptide inhibits degranulation and changes granular content of mast cells: a potential therapeutic strategy in controlling septic shock. Peptides 2000; 21: 81-89.

39 Delgado M, Abad C, Martinez C, Leceta J, Gomariz RP: Vasoactive intestinal peptide prevents experimental arthritis by downregulating both autoimmune and inflammatory components of the disease. Nat Med 2001; 7: 563-568.

40 Gonzalez-Rey E, Chorny A, Varela N, Del Moral RG, Delgado M: Therapeutic effect of cortistatin on experimental arthritis by downregulating inflammatory and Th-1 responses. Ann Rheum Dis 2007; 66: 582-588.
41 Gonzalez-Rey E, Chorny A, Varela N, O’Valle F, Delgado M: Therapeutic effect of urocortin on collagen-induced arthritis by downregulating inflammatory and Th1 response and inducing regulatory T cells. Arthritis Rheum 2007; 56: 531-543.

42 Gonzalez-Rey E, Chorny A, O’Valle F, Delgado $\mathrm{M}$ : Adrenomedullin protects from experimental arthritis by downregulating inflammation and Th1 response and inducing regulatory $\mathrm{T}$ cells. Am J Pathol 2007; 170: 263-271.

43 Gonzalez-Rey E, Varela N, Sheibanie AF, Chorny A, Ganea D, Delgado M: Cortistatin, a new anti-inflammatory peptide with therapeutic action in inflammatory bowel disease. Proc Natl Acad Sci USA 2006; 103: 4228 4233.

44 Gonzalez-Rey E, Fernandez-Martin A, Chorny A, Delgado M: Therapeutic effect of urocortin and adrenomedullin in a murine model of Crohn's disease. Gut 2006; 55: 824 832.

45 Abad C, Martinez C, Juarranz MG, Arranz A, Leceta J, Delgado M, Gomariz RP: Therapeutic effects of vasoactive intestinal peptide in the trinitrobenzene sulfonic acid mice model of Crohn's disease. Gastroenterology 2003; 124: 961-971.

46 Gonzalez-Rey E, Chorny A, Delgado M: Therapeutic action of ghrelin in a mouse model of colitis. Gastroenterology 2006; 130: 1707-1720.

47 Poliak S, Mor F, Conlon P, Wong T, Ling N, Rivier J, Vale W, Steinman L: Stress and autoimmunity: the neuropeptides corticotropinreleasing factor and urocortin suppress encephalomyelitis via effects on both the hypothalamic-pituitary-adrenal axis and the immune system. J Immunol 1997; 158: 5751-5756.

48 Li H, Mei Y, Wang Y, Xu L: Vasoactive intestinal polypeptide suppressed experimental autoimmune encephalomyelitis by inhibiting $\mathrm{T}$ helper 1 responses. J Clin Immunol 2006; 26: 430-437.

49 Gonzalez-Rey E, Fernandez-Martin A, Chorny A, Martin J, Pozo D, Ganea D, Delgado M: Therapeutic effect of vasoactive intestinal peptide on experimental autoimmune encephalomyelitis: downregulation of inflammatory and autoimmune responses. Am J Pathol 2006; 168: 1179-1188.

50 Herrera JL, Fernandez-Montesinos R, Gonzalez-Rey E, Delgado M, Pozo D: Protective role for plasmid DNA-mediated VIP gene transfer in non-obese diabetic mice. Ann NY Acad Sci 2006; 1070: 337-341.

51 Lodde BM, Mineshiba F, Wang J, Cotrim AP, Afione S, Tak PP, Baum BJ: Effect of human vasoactive intestinal peptide gene transfer in a murine model of Sjörgre's disease. Ann Rheum Dis 2006; 65: 195-200.

52 Kojima M, Ito T, Oono T, Hisano T, Igarashi H, Arita Y, Kawabe K, Coy DH, Jensen RT, Nawata H: VIP attenuation of the severity of experimental pancreatitis is due to VPAC1 receptor-mediated inhibition of cytokine production. Pancreas 2005; 30: 62-70.

53 Dembinski A, Warzecha Z, Ceranowicz P, Tomaszewska R, Stachura J, Konturek SJ, Kon- turek PC: Ghrelin attenuates the development of acute pancreatitis in rat. J Physiol Pharmacol 2003; 54: 561-573.

54 Nishida T, Taylor AW: Specific aqueous humor factors induce activation of regulatory $\mathrm{T}$ cells. Invest Ophthalmol Vis Sci 1999; 40: 2268-2274.

55 Keino H, Kezuka T, Takeuchi M, Yamakawa N, Hattori T, Usui M: Prevention of experimental autoimmune uveoretinitis by vasoactive intestinal peptide. Arch Ophthalmol 2004; 122: 1179-1184.

56 Delgado M, Muñoz-Elías EJ, Gomariz RP, Ganea D: Vasoactive intestinal peptide and pituitary adenylate cyclase-activating polypeptide enhance IL-10 production by murine macrophages: in vitro and in vivo studies. J Immunol 1999; 162: 1707-1716.

57 Delgado M, Munoz-Elias EJ, Gomariz RP, Ganea D: VIP and PACAP inhibit IL-12 production in LPS-stimulated macrophages: subsequent effect on IFN $\gamma$ synthesis by $\mathrm{T}$ cells. J Neuroimmunol 1999; 96: 167-181.

58 Delgado M, Jonakait GM, Ganea D: Vasoactive intestinal peptide and pituitary adenylate cyclase-activating polypeptide inhibit chemokine production in activated microglia. Glia 2002; 39: 148-161.

59 Wang MJ, Lin SZ, Kuo JS, Hang HY, Tzeng SF, Liao $\mathrm{CH}$, Chen DC, Chen WF: Urocortin modulates inflammatory response and neurotoxicity induced by microglial activation. J Immunol 2007; 179: 6204-6214.

60 Delgado M, Gonzalez-Rey E: Vasoactive intestinal peptide inhibits cycloxygenease $2 \mathrm{ex}$ pression in activated macrophages, microglia and dendritic cells. Brain Behav Immun 2008; 22: 35-41.

61 Dello Russo C, Lisi L, Navarra P, Tringali G: Diverging effects of cortistatin and so-matostatin on the production and release of prostanoids from rat cortical microglia and astrocytes. J Neuroimmunol 2009; 213: 7883.

62 Gonzalez-Rey E, Varela N, Chorny A, Delgado M: Therapeutic approaches of vasoactive intestinal peptide as a pleiotropic immunomodulator. Curr Pharm Des 2007; 13: 11131139.

63 Tumer C, Bilgin HM, Obay BD, Diken H, Tasdemir E, Sermet A: Effect of ghrelin administration on phagocytic activity in acute coldrestraint stress exposed rats. Regul Pept 2007; 138: 113-117.

64 Tsatsanis C, Androulidaki A, Dermitzaki E, Charalampopoulos I, Spiess J, Gravanis A, Margioris NA: Urocortin 1 and urocortin 2 induce macrophage apoptosis via CRFR2. FEBS Lett 2005; 579: 4259-4264.

65 Chorny A, Delgado M: Neuropeptides rescue mice from lethal sepsis by down-regulating the secretion of the late-acting inflammatory mediator high mobility group box 1. Am J Pathol 2008; 172: 1297-1307.

66 Chorny A, Anderson P, Gonzalez-Rey E, Delgado M: Ghrelin protects against experimental sepsis by inhibiting high mobility group box 1 release and by killing bacteria. J Immunol 2008; 180: 8369-8377. 
67 Hirayama T, Kawabe T, Matsushima M, Nishimura Y, Kobe Y, Ota Y, Baba K, Takagi $\mathrm{K}$ : Ghrelin and obestatin promote the allergic action in rat peritoneal mast cells as basic secretagogues. Peptides 2010; 31: 2109-2113.

68 Walsh SK, Kane KA, Wainwright CL: Mast cells, peptides and cardioprotection - an unlikely marriage? Auton Autacoid Pharmacol 2009; 29: 73-84.

-69 Wu Y, Hu J, Zhang R, Zhou C, Xu Y, Guan X, Li S: Enhanced intracellular calcium induced by urocortin is involved in degranulation of rat lung mast cells. Cell Physiol Biochem 2008; 21: 173-182.

70 Miksa M, Wu R, Cui W, Dong W, Das P, Simms HH, Ravikuman TS, Wang P: Vasoactive hormone adrenomedullin and its binding protein: anti-inflammatory effects by up-regulating peroxisome proliferator-activating receptor- $\gamma$. J Immunol 2007; 179: 6263-6272.

71 Cheng B, Wan J, Wang Y, Mei C, Liu W, Ke L, He P: Ghrelin inhibits foam cell formation via simultaneously down-regulating the expression of acyl-coenzyme A:cholesterol acyltransferase 1 and up-regulating adenosine triphosphate-binding cassette transporter A1. Cardiovasc Pathol 2009; 19:e159-e166.

-72 Delgado M, Reduta A, Sharma V, Ganea D: VIP/PACAP oppositely affect immature and mature dendritic cell expression of CD80/ CD86 and the stimulatory activity of CD4+ T cells. J Leukoc Biol 2004; 75: 1122-1130.

77 Delgado M, Gonzalez-Rey E, Ganea D: VIP/ PACAP preferentially attract Th2 versus Th1 cells by differentially regulating the production of chemokines by dendritic cells. FASEB J 2004; 18: 1453-1455.

74 Shibata M, Hisajima T, Nakano M, Goris RC, Funakoshi K: Morphological relationships between peptidergic nerve fibers and immunoglobulin A-producing lymphocytes in the mouse intestine. Brain Behav Immun 2008; 22: $158-166$.

-75 Gonzalez-Rey E, Fernandez-Martin A, Chorny A, Delgado M: Vasoactive intestinal peptide induces $\mathrm{CD} 4+\mathrm{CD} 25+$ regulatory $\mathrm{T}$ cells with therapeutic effect on collagen-induced arthritis. Arthritis Rheum 2006; 54: 864-876.

-76 Fernandez-Martin A, Gonzalez-Rey E, Chorny A, Ganea D, Delgado M: Vasoactive intestinal peptide induces regulatory $\mathrm{T}$ cells during experimental autoimmune encephalomyelitis. Eur J Immunol 2006; 36: 318-326.

-77 Delgado M, Chorny A, Gonzalez-Rey E, Ganea $D$ : Vasoactive intestinal peptide generates $\mathrm{CD} 4+\mathrm{CD} 25+$ regulatory T cells in vivo. J Leukoc Biol 2005; 78: 1327-1338.

78 Chorny A, Gonzalez-Rey E, Fernandez-Martin A, Pozo D, Ganea D, Delgado M: Vasoactive intestinal peptide induces regulatory dendritic cells with therapeutic effects on autoimmune disorders. Proc Natl Acad Sci USA 2005; 102: 13562-13567.

79 Delgado M, Gonzalez-Rey E, Ganea D: The neuropeptide vasoactive intestinal peptide generates tolerogenic dendritic cells. J Immunol 2005; 175: 7311-7324.
80 Gonzalez-Rey E, Chorny A, Fernandez-Martin A, Ganea D, Delgado M: Vasoactive intestinal peptide generates human tolerogenic dendritic cells that induce CD4 and CD8 regulatory T cells. Blood 2006; 107: 3632-3638.

81 Gomariz RP, Arranz A, Abad C, Torroba M Martinez C, Rosignoli F, Garcia-Gómez M, Leceta J, Juarranz Y: Time-course expression of Toll-like receptors 2 and 4 in inflammatory bowel disease and homeostatic effect of VIP. J Leukoc Biol 2005; 78: 491-502.

82 Delgado M, Leceta J, Abad C, Martinez C, Ganea D, Gomariz RP: Shedding of membrane-bound CD14 from lipopolysaccharidestimulated macrophages by vasoactive intestinal peptide and pituitary adenylate cyclaseactivating polypeptide. J Neuroimmunol 1999; 99: 61-71.

83 Martinez C, Abad C, Delgado M, Arranz A, Juarranz MG, Rodriguez-Henche N, Brabet $\mathrm{P}$, Leceta J, Gomariz RP: Anti-inflammatory role in septic shock of pituitary adenylate cyclase-activating polypeptide receptor. Proc Natl Acad Sci USA 2002; 99: 1053-1058.

$>84$ Szema AM, Hamidi SA, Lyubsky S, Dickman KG, Mathew S, Abdel-Razek T, Chen JJ, Waschek JA, Said SI: Mice lacking the VIP gene show airway hyperresponsiveness and airway inflammation, partially reversible by VIP. Am J Physiol Lung Cell Mol Physiol 2006; 291:L880-L886.

85 Hataya Y, Akamizu T, Hosoda H, Kanamoto N, Moriyama K, Kangawa K, Takaya K, Nakao K: Alterations of plasma ghrelin levels in rats with lipopolysaccharide-induced wasting syndrome and effects of ghrelin treatment on the syndrome. Endocrinology 2003; 144: 5365-5371.

86 Nishi Y, Isomoto H, Ueno H, Ohnita K, Wen CY, Takeshima F, Mishima R, Nakazato M, Kohno S: Plasma leptin and ghrelin concentrations in patients with Crohn's disease. World J Gastroenterol 2005; 11: 7314-7317.

87 Tan YV, Abad C, Lopez R, Dong H, Liu S, Lee A, Gomariz RP, Leceta J, Waschek JA: Pituitary adenylyl cyclase-activating polypeptide is an intrinsic regulator of Treg abundance and protects against experimental autoimmune encephalomyelitis. Proc Natl Acad Sci USA 2009; 106: 2012-2017.

88 Abad C, Tan YV, Lopez R, Nobuta H, Dong H, Phan P, Feng JM, Campagnoni AT, Waschek JA: Vasoactive intestinal peptide loss leads to impaired CNS parenchymal T-cell infiltration and resistance to experimental autoimmune encephalomyelitis. Proc Natl Acad Sci USA 2010; 107: 19555-19560.

-89 Youm YH, Yang H, Sun Y, Smith RG, Manley NR, Vandanmagsar B, Dixit VD: Deficient ghrelin receptor-mediated signaling compromises thymic stromal cell microenvironment by accelerating thymic adiposity. J Biol Chem 2009; 284: 7068-7077.

90 Jégou S, Javoy-Agid F, Delbende C, Tranchand-Bunel D, Coy DH, Agid Y, Vaudry H: Regional distribution of vasoactive intestinal peptide in brains from normal and parkinsonian subjects. Peptides 1988; 9: 787-793.
-91 Arai H, Moroji T, Kosaka K: Somatostatin and vasoactive intestinal polypeptide in postmortem brains from patients with $\mathrm{Alz}$ heimer-type dementia. Neurosci Lett 1984; 52: 73-78.

92 Bangale Y, Karle S, Planque S, Zhou YX, Taguchi H, Nishiyama Y, Li L, Kalaga R, Paul $\mathrm{S}$ : VIPase autoantibodies in Fas-defective mice and patients with autoimmune disease. FASEB J 2003; 17: 628-635.

$\$ 93$ Juarranz Y, Gutiérrez-Cañas I, Santiago B, Carrión M, Pablos JL, Gomariz RP: Differential expression of vasoactive intestinal peptide and its functional receptors in human osteoarthritic and rheumatoid synovial fibroblasts. Arthritis Rheum 2008; 58: 1086-1095.

94 Delgado M, Robledo G, Rueda B, Varela N, O'Valle F, Hernandez-Cortes P, Caro M, Orozco G, Gonzalez-Rey E, Martin J: Genetic association of vasoactive intestinal peptide receptor with rheumatoid arthritis: altered expression and signal in immune cells. Arthritis Rheum 2008; 58: 1010-1019.

95 Sun W, Hong J, Zang YC, Liu X, Zhang JZ: Altered expression of vasoactive intestinal peptide receptors in $\mathrm{T}$ lymphocytes and $\mathrm{ab}$ errant Th1 immunity in multiple sclerosis. Int Immunol 2006; 18: 1691-1700.

$>96$ El Karim IA, Linden GJ, Orr DF, Lundy FT: Antimicrobial activity of neuropeptides against a range of micro-organisms from skin, oral, respiratory and gastrointestinal tract sites. J Neuroimmunol 2008; 200: 11-16.

$\$ 97$ Allaker RP, Kapas S: Adrenomedullin and mucosal defence: interaction between host and microorganism. Regul Pept 2003; 112: 147-152.

98 Rauch I, Holzmeister S, Kofler B: Anti-Candida activity of alpha-melanocyte-stimulating hormone (alpha-MSH) peptides. J Leukoc Biol 2009; 85: 371-372.

$\checkmark 99$ Delgado M, Anderson P, Garcia-Salcedo JA, Caro M, Gonzalez-Rey E: Neuropeptides kill African trypanosomes by targeting intracellular compartments and inducing autophagic-like cell death. Cell Death Differ 2009; 16: 406-416.

100 Prasse A, Zissel G, Lützen N, Schupp J, Schmiedlin R, Gonzalez-Rey E, RensingEhl A, Bacher G, Cavalli V, Bevec D, Delgado M, Müller-Quernheim J: Inhaled vasoactive intestinal peptide exerts immunoregulatory effects in sarcoidosis. Am J Respir Crit Care Med 2010; 182: 540-548.

101 Kodama T, Ashitani J, Matsumoto N, Kangawa K, Nakazato M: Ghrelin treatment suppresses neutrophil-dominant inflammation in airways of patients with chronic respiratory infection. Pulm Pharmacol Ther 2008; 21: 774-779.

102 Blakeney JS, Fairlie DP: Nonpeptide ligands that target peptide-activated GPCRs in inflammation. Curr Med Chem 2005; 12: 3027-3042.

103 Gonzalez-Rey E, Delgado-Maroto V, Souza Moreira L, Delgado M: Neuropeptides as therapeutic approach to autoimmune diseases. Curr Pharm Des 2010; 16: 3158-3172. 